\title{
From the Editor of Sexuality and Disability: The Power of Knowledge, Awareness and Communication to Expand Attitudes, Enhance Perceptions and Increase Access
}

\author{
Sigmund Hough ${ }^{1}$
}

Published online: 4 August 2016

(C) Springer Science+Business Media New York 2016

The journal of Sexuality and Disability remains a professional home for many, and a place of professional rejuvenation and professional exploration for still more. If you are new to the journal, we offer to you a "BIG WELCOME" to participate as a reader, author, academician, clinician, educator, service provider, researcher, advocate, and individual or individuals seeking information. Over decades of contribution to the literature on sexuality and disability, we have been a part of the growth and understanding. Now most importantly, we continue to be a part of change in how we look and examine the topic, the need, and the response in terms of best practice-evidence based approaches. With the intelligence, experience, motivation and commitment from our authors, readership, peer reviewers and editorial board, and resources with guidance from the Springer Staff, our journal's mission continues to be strong and meaningful.

The power of knowledge, awareness and communication brings achievement and risk at times. Challenge to "what is" and "that's how we do it" can bring worry and fear about change and losing control. However, change brings new opportunities not only in thinking but also in behavior. Acknowledging that not all change is good, highlights a required principle of fair process in working towards enlightenment. Not an easy task, but an inherent task when we research, publish and present is to help make our surroundings a better place. So we continue to expand attitudes, enhance perceptions and increase access.

The journal Sexuality and Disability continues to provide original impact articles addressing the mental health and medical aspects of sexuality in relation to rehabilitation, hospital, academic and community settings, publishing up-to-date articles, case studies, clinical practice reports, reviews, featured articles, historical articles, special grand rounds topics, brief research reports and survey data reports. Value benefit is provided to authors through worldwide electronic exposure and professional access, while readership gains from scholarly contributions to advance the field through research, best-practice and

Sigmund Hough

Sigmund_Hough@hms.harvard.edu

1100 Cummings Center, Suite 207, Beverly, MA 01915-6144, USA 
educational articles. The refined lens of individual contributions from the local and international community continues to deliver a wealth of information on the topic of sexuality and disability for the reader. Thank you for joining our community. 